\title{
A Study on the Intestinal Parasitic Infections among Elementary School Students at a District (Silvana) In Urmia, West Azerbaijan
}

\author{
Hazrati Tappeh $\mathrm{KH}^{1}$, Mostaghim $\mathrm{M}^{2}$, Hanifian $\mathrm{H}^{3 *}$, Khalkhali $\mathrm{H}^{4}$, Mousavi $\mathrm{J}^{5}$ \\ ${ }^{1}$ Parasitology and mycology department, Urmia University of Medical Sciences, Urmai, Iran \\ ${ }^{2}$ Parasitology and mycology department, Urmia University of Medical Sciences, Urmai, Iran \\ ${ }^{3}$ Parasitology and mycology department, Tehran University of Medical Sciences, Tehran, Iran \\ ${ }^{4}$ Epidemiology department, Urmia University of Medical Sciences, Urmai, Iran \\ ${ }^{5}$ Internal and infectious disease department, Urmia University of Medical Sciences, Urmai, Iran \\ *Corresponding author: Hanifian H, Tehran University of Medical Sciences, Tehran-Iran, Email: Haleh.hanifian@ gmail.com, \\ Zip Code: 5714783734, Tel: +98 9143400862
}

\begin{abstract}
Background \& Aims: According to the increasing rate of intestinal parasitic infection in rural areas compared to urban areas, this study deals with the prevalence of intestinal parasitic infections in elementary school students in Silvana rural district.
\end{abstract}

Material and Methods: 350 students of both sexes were selected randomly. All samples were studied with routine parasitology methods, such as wet mount method and formalin - ether concentration.

Microscopic examination of Enterobius vermicularis and Taenia saginata eggs carried out with 10 and 40 lenses.

Results: The study showed that the total prevalence of intestinal parasitic infections is $52 \%$,

And prevalence of protozoan infections (50.57\%) is more than helminthes infection (Oxyuris 24.9\%, Ascaris 0.28\%, Hymenolepis nana 1.14\%).Relative frequencies of intestinal protozoan were as follows: Giardia lamblelia (37.57\%), Entamoeaba coli (26.86\%), Iodamoeba butchlii (8\%), Blastocystis hominis (4.28\%). The study showed a significant opposite correlation between mother's education and prevalence of intestinal parasitic infections in subjects $(\mathrm{P}$ - value $=0.03$ ).

Conclusion: The result of the present study indicated the high prevalence of protozoan infections and Oxyuriasis in this area. Other studies and present study indicate the world wide spread of intestinal parasitic infections.

Keywords: Intestinal parasitic infections, Epidemiology, Elementary school students

Received 29 April 2015, Accepted for publication 1 July 2015

\section{Introduction}

Intestinal parasites with worldwide prevalence are regarded as the most important health and economic problems (1). It has been estimated that $1 / 3$ of people, especially children in developing countries, are suffering from intestinal parasites which might have a negative effect on decreasing working ability, IQ and body development (2). Intestinal parasites are effective for observing some materials which are important in the prevention of oligemia and there is a relationship between parasites and diarrhea, malnutrition, and disposition to other infections (3).

The prevalence of intestinal parasites depends on many factors such as filtered water benefit, swage filtration system, drainage, extensive training for health effects on mass media, promotion of public health, accessibility of health and media services as well as suitable construction materials in dwelling, location of restroom in houses, along with feeding conditions such as meat and vegetable cooking methods (4).

Some parasitic infections are under control or they have been decreasing in recent years. Compared to the last two decades, health level promotion and the following hygienic points in urban and some rural areas have decreased the diseases (5). However, they are considered important health indexes and their changeability in various societies from time to time explains the necessity of studying the prevalence rate 
and getting to know the epidemic aspects and the relationship with environmental factors $(6,7)$.

Permanence of parasite infections in an area is related to unmarked infections and lack of diagnostic methods and treatment in infected people. In all societies, children and teens are exposed to danger more than others; so, this age group is in priority in studies and elementary schools are the best places for this kind of studies.

This study was performed on Silvana elementary school students to find out the prevalence rate of intestinal infections. The reasons of selecting Silvana as studying area were the lack of health services and water filtration systems, poverty, illiteracy, and crowded families with young uninformed children, not up to date agriculture and husbandry industry which prepare a suitable environment for parasitic infections.

\section{Materials and Methods}

Considering the studied factors such as the lack of health services and water filtration systems, poverty, illiteracy, and crowded families, and ... the study was undertaken on Silvana elementary school students to find out the of prevalence of intestinal infections. This region of the study in located in Urmia with its extended areas or sub-divisions, including Margevar, Dasht, and Targevar, which are located on the boundary of Turkey (and Iraq in Mergevar case).

The students in this study were 3833 males, and 3153 females in 108 schools and 339 classes.

In this study, 11 out of 55 villages were selected randomly with more than 20 families. All the elementary schools in these villages were included in the study.

The subjects were selected randomly based on the number of the students in a class and their sex. Then, the parents were invited by the cooperation of principals in order to clarify the aim of the study and train them how to take the Scotch tape and feces samples from their children. For the research, they filled out a questionnaire and included their full name, sex, education level, age, and number of children.

In this study, Scotch tape slides and feces containers, which were labeled with the name of students and their grade at the school, were collected twice. The samples were gathered on two consecutive days and taken to Parasitology and Mycology Laboratory, Faculty of Medicine. First, the samples were analyzed by wetmount method and then, for increasing the exactness of the test, formalin-ether concentration was used. The Scotch tapes were studied by a microscope with 10 and 40 lenses. At the end of the study, all the data were analyzed in SPSS/win program.

\section{Results}

At the present study which was carried out in Silvana district with its three sub districts of Mergever, Dasht, and Tergever, 11 villages were selected randomly, then all of the elementary schools in this area were included in the study. The selection of the students was randomly performed based on the total student's population in each school. As some students did not cooperate, we decided to start our examination on 436 students by training their parents how to take Scotch tape and how to fill the feces containers. In addition, they filled out our questionnaire. However, some of them did not cooperate and 86 students left the study. Thus, the study was continued with 350 students; only 229 of them were able to perform tape method.

The results obtained from the feces examinations (Table 1) show that Ordougah and Toula villages had respectively maximum $(73.5 \%)$ and minimum (25\%) rates of infection. Total rate of infection was $52.6 \%$ (47.4\% $-57.8 \%$ by $95 \%$ positiveness index).

Diagrams show the abundance distributions of infected subjects according to the method of diagnosis.

According to the type of parasites, the rate of infection in feces examination by formalin-ether method was respectively Giardia lambelia (36.57\%), Entamoeba coli $(26.86 \%)$, Iodomoeba butschlii (8\%), Blastocystis hominis (4.28\%), Hymenolepis nana (1.71\%), and Ascaris (0.28\%)(Table 2).

According to Scotch tape method, the best way for Oxyuris diagnosis, the rate of infection was $24.9 \%$ among the subjects. 
The abundance distribution of parasites among the students categorized as male and female. The results demonstrated the higher rate of infection in the males $(54.8 \%)$ rather than females $(49.7 \%)$, which was not a significant differential factor between them $(\mathrm{P}$-value= 0.34).

In this study, we categorized the students based on their family population, and then we could study its correlation with the rate of infection. More populated families (more than 7 members) were 56\% infected, less populated families(less than 5 members) were $40 \%$ infected, and the average ones (5-7 members) were $54.4 \%$ infected. (P-value=0.09).

According to this study, there was significant negative correlation between the literacy level of mothers and infection rate in the mentioned students $(\mathrm{P}$ value $=0.03)$.

Table 1: Abundance distribution of parasitic intestinal infections among the elementary school Students in Silvana by

\begin{tabular}{lllllll}
\multicolumn{1}{c}{$\begin{array}{c}\text { The name of } \\
\text { village }\end{array}$} & \multicolumn{2}{c}{ Infected } & \multicolumn{2}{c}{ Non-infected } & \multicolumn{3}{c}{ Total } \\
\cline { 2 - 7 } \multicolumn{1}{c}{ Abundance } & Percent & Abundance & Percent & Abundance & Percent \\
\hline Dizaj & 58 & 63.7 & 33 & 36.3 & 91 & 100 \\
Zevveh & 12 & 52.2 & 11 & 48.8 & 23 & 100 \\
Ordougah & 25 & 73.5 & 9 & 26.5 & 34 & 100 \\
Hashem abad & 13 & 54.2 & 11 & 45.8 & 24 & 100 \\
Razgah & 10 & 52.6 & 9 & 47.4 & 19 & 100 \\
Raj an & 29 & 52.7 & 26 & 47.3 & 55 & 100 \\
Silvana & 17 & 42.5 & 23 & 57.5 & 40 & 100 \\
Anbi & 8 & 32 & 17 & 68 & 25 & 100 \\
Toula & 3 & 25 & 9 & 75 & 12 & 100 \\
Movana & 6 & 27.3 & 16 & 22.7 & 22 & 100 \\
Debreh & 3 & 60 & 2 & 40 & 5 & 100 \\
Total & 184 & 52.6 & 166 & 47.4 & 350 & 100 \\
\hline
\end{tabular}

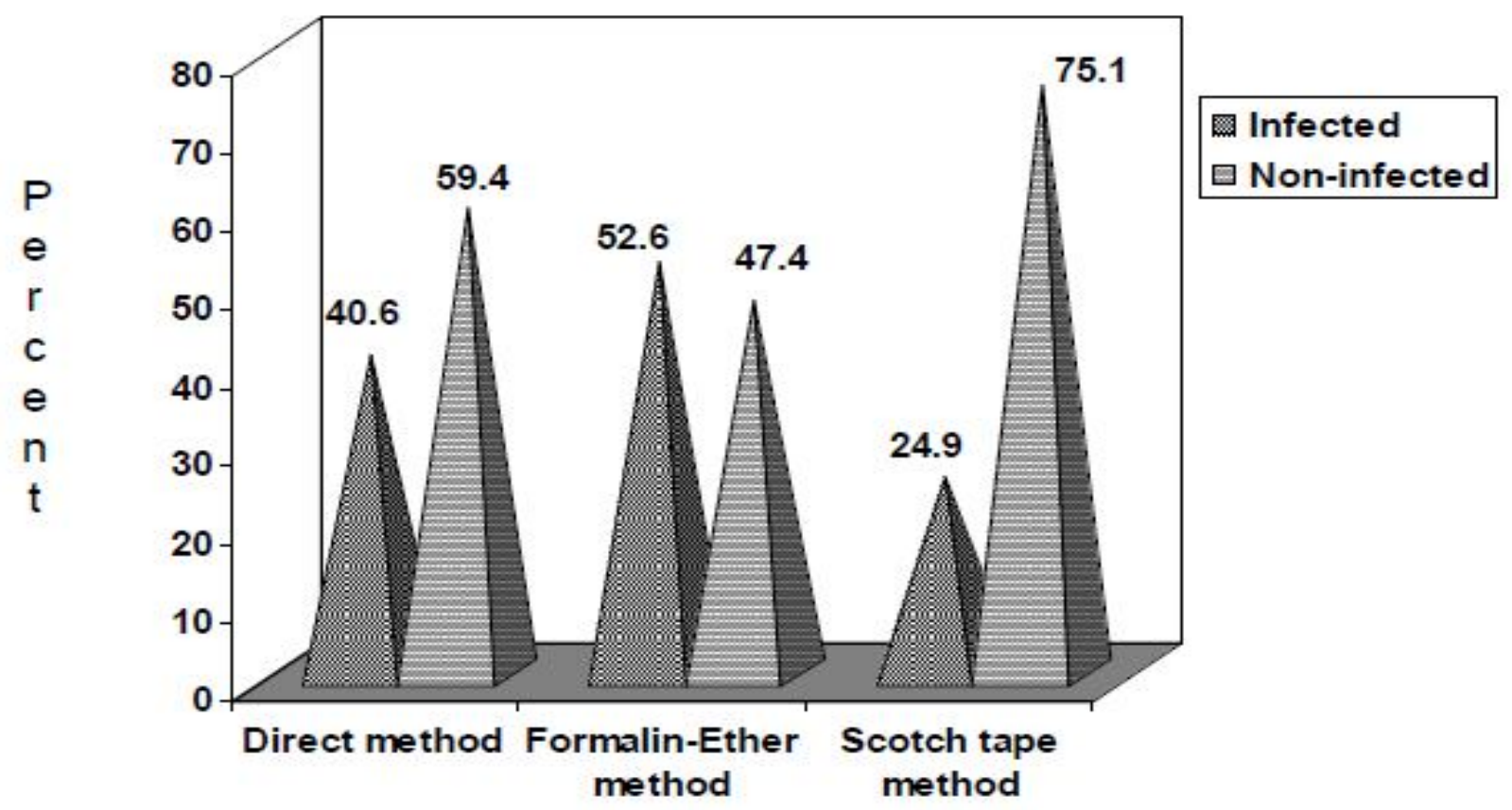

\section{Diagnosis Method}

Diagram 1: Abundance distributions of infected subject according to the method of diagnosis 
Table 2: Prevalence distribution in subjects according to 3 direct, Formalin-Ether and Scotch tape methods

\begin{tabular}{|c|c|c|c|c|c|c|c|c|c|}
\hline \multirow{3}{*}{ Parasites } & \multirow{3}{*}{$\begin{array}{c}\begin{array}{c}\text { Direct } \\
\text { method }\end{array} \\
\text { cases }\end{array}$} & & \multicolumn{3}{|c|}{ Formalin-ether } & \multirow{2}{*}{\multicolumn{2}{|c|}{$\begin{array}{c}\text { tape } \\
* * \text { method }\end{array}$}} & \multicolumn{2}{|c|}{ Scotch } \\
\hline & & & & & * method & & & & \\
\hline & & rate & & cases & rate & & cases & & rate \\
\hline Giardia lambelia & 100 & 28.57 & 128 & & 36.27 & 0 & & 0 & \\
\hline Entamoeba coli & 49 & 14 & 94 & & 26.86 & 0 & & 0 & \\
\hline Iodomoeba butchlii & 12 & 3.43 & 28 & & 8 & 0 & & 0 & \\
\hline Blastocystis hominis & 9 & 2.57 & 15 & & 4.28 & 0 & & 0 & \\
\hline Hymnolepis nana & 4 & 1.14 & 6 & & 1.71 & 0 & & 0 & \\
\hline Ascaris lumbericoides & 0 & 0 & 1 & & 0.28 & 0 & & 0 & \\
\hline Oxyuris & 0 & 0 & 0 & & 0 & 57 & & 24.9 & \\
\hline
\end{tabular}

* Prevalence of infection was calculated based on 350 students

** Pre valence of infection was calculated based on 229 students

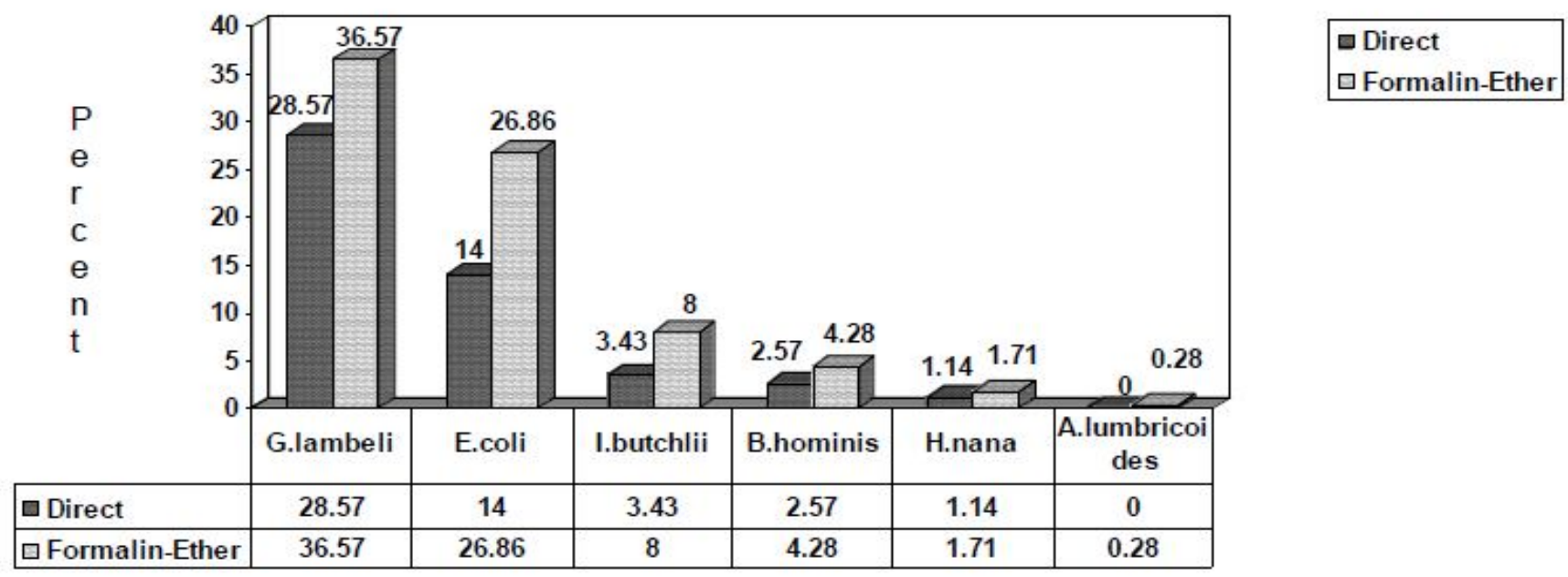

\section{Diagnosis Method}

Diagram 2: Abundance distributions of infected subject according to the method of diagnosis in Silvana elementary school students

\section{Discussion}

In this study, 700 feces and 458 Scotch tape slides were collected twice from 350 students of Silvana distract. The results of the present investigation indicated that total prevalence of intestinal parasites, whether pathogen or non-pathogen, among the elementary school students in Silvana was $52.6 \%$ at $95 \%$ confidence interval $(47.4 \%, 57.8 \%)$, and the prevalence of protozoan infection was $50.57 \%$, which was more than helminth infections $(24.9 \%$ oxyuris, $1.44 \%$ Hymenolepis nana, and $0.28 \%$ Ascaris lumbricoides).

In a study conducted by Hazrati Tappeh (2004), it was demonstrated that the prevalence of protozoan infection was $29.1 \%$ in Nazloo, a region in the north of
Urmia. Also, Giardia with $17.7 \%$ and Entamoeba coli with $16.23 \%$ of incidence had the biggest shares based on the reported infections (8).

Comparisons of the studies indicated that Giardia with $36.57 \%$ and Entamoeba coli with $26.86 \%$ were higher than other infections in the region, which can be explained by its urban structure, cultural differences, high rate of poverty, lack of health services, etc.

Rate of helminth infections in Nazloo region, reported by Hazrati Tappeh, was: Oxyure $28.4 \%$ and Hymenolepis nana $0.4 \%$, with no other infection (9). In the present study, the rates of different infections were: Oxyuris $24.9 \%$, Hymenolepis nana $1.44 \%$, and Ascaris lumbericoides $0.28 \%$. 
Several studies until 1997 in Hamadan Province, Iran, have shown that the prevalence of Ascaris lumbericoides has been higher than other regions in Iran. In those years, the rate of infection was $40 \%$ in urban and $75 \%$ in rural regions. By performing different hygienic methods such as water and sewage filtration system, health training, promoting hygienic behaviors in the society to defeat parasitic infections, especially Ascariasis, the rate of infection declined to $6 \%$ in 1999 (10). In this study, the rate of Ascariasis was reported as $0.28 \%$ in Silvana which was very low due to the avoidance of using stool as a fertilizer in the farms.

In 2001, Sharifi Saret al. worked on the prevalence of intestinal parasites among elementary school students in Bandar Abbas. In this study, 1369 subjects were selected randomly and examined. The results showed $48.4 \%$ infection (34.18\% protozoan and $5.91 \%$ helminth). In the mentioned study, Giardia had the maximum rate $(17.23 \%)(11)$.

Kebatereine et al. investigated the prevalence of helminth infections among the students in the south of Oganda in 2001. In their survey, 18 regions of the country were studied. They found that $55.9 \%$ of the students were infected by Oxyuris, Ascaris lumbericoides, and Trichuris trichiura (Ascaris lumbericoides $17.5 \%$, Trichuris trichiura $7.3 \%$, and hook worms $44.5 \%$ ) (12).

In a study by Nazari Pouya et al., on elementary school students, 752 out of 1200 samples were found to be infected ( $51.7 \%$ male and $48.3 \%$ female). In addition, the rate of infection was $46.3 \%$ in the urban regions, and $50.61 \%$ in the rural areas. In their study, there was no significant relationship between sex and infection $(\mathrm{P}=0.34)(13)$.

In another study by Okyay et al., 456 elementary school students were studied in Aydin, Turkey. The results reported $31.8 \%$ of total infection; $6.1 \%$ Giardia lambelia, 4.6\% Entamoeba coli, and 13.8\% Entrobius vermicularis (14). The results of the present study indicated a high rate of some intestinal infections such as Giardiasis in Silvana district. In line with the present study, along with some studies in different countries, parasitic intestinal infections are shown to have a worldwide distribution, and they are among the most important health indexes. Finally, worth to mention that in different societies and age groups, still protozoan infections especially Giardiasis and Amoebiasis are considered to be very serious problems for the human societies.

\section{Conflicts of Interest:}

The authors declare no conflict of interest.

\section{References}

1. Mandell JL, Bennet JE, Dolin Reds, : Introduction to helminthes infections, Principles and practice of infectious diseases. New Yourk: Churchill Livingston; 2004. P.293794.

2. Cox FEG, Wakelin D, Gillespie SH, Despommier DD. Topley and Wilson's Microbiology and microbial infections parasitology, classification and introduction to the parasitic protozoa. Washington D.C: ASM press; 2005.P.159-65.

3. Ghorbani R, Pazouki R, Ahmadian A.The prevalence of intestinal parasites and relative factors in childeren below 2 years old in the urban areas of Semnan In 1996-97. J Gorgan Univ Med Sci 1999;1(3 \&4):40.

4. Esmaeili Rastaghi AR, Asmar A. Prevalence of intestinal parasites in primary school students in Golestan province of Iran. 3rd International medical parasitology congress Sari-Iran: 2000.P. 194.

5. Maraghi Sh, Charim J, Memarpour M. Prevalence of intestinal parasitic infections in patients of Golestan and Sina laboratory in Ahvaz 1999.3rd international medical parasitology congress Sari-Iran: 2000.P.197.

6. Davami MH, Mostofi M, Modaresi M. An investigation on intestinal parasitic infection and the effective demographic factors in children in Shahrak-e-Valiasr Arak during 1999. J Arak Univ Med Sci.1999; 5(2):5-10.

7. Daneshvar P, Baghayi M, Mirloumi M, Mahmoudi M. Intestinal parasitic prevalence in rural area children, Mobarakeh, Isfahan 1997. J Isfahan Univ Med Sci. 1997; 6(3): 104-7.

8. Hazrati Tappeh Kh. The prevalence of intestinal parasitic infection in students of primary schools in Nazloo region 
in Urmia during 2004-2005. Urmia Med J. 2005; 16(4): 213-7.

9. Hazrati Tappeh Kh, Salari Sh, Esmaeili R, Mohammadzadeh H. Prevalence of children infected by Oxyuris in Orumiyeh kindergartens and the ways to control that. J Kordestan Univ Med Sci 2003; 8(26): 2935.

10. Fallah M, Mir Arab A, Jaalian F, Ghaderi A. Epidemiological study of Ascariasis in Hamadan city, west of Iran, 2001. J Hamadan Univ Med Sci 2004; 11(31): 55-60.

11. Sharifi Sar Kh, Madani A. Prevalence of intestinal parasites in primary school pupils of Bandar Abbas. J
Hormozgan Univ Med Sci 2001; 5(4): 79-85.

12. Kabatereine NB, Tukahebwa EM. Epidemiology of intestinal helminthes infections among school children in southern Uganda.East Afr Med J. 2001; 78(6): 283-6.

13. Nazari Pouya M, Khani H, Khazan H. Prevalence of intestinal parasites in primary school (7-14 year) pupils of Fariman city, 1993-94. 3rd international medical parasitology congress Sari-Iran: 2000.P.65.

14. Okyay P, Ertug S, Gultekin B, Onen O, Beser E. Intestinal parasites prevalence and related factors in school children, a western city sample--Turkey. BMC Public Health. 2004 22; 4:64. 